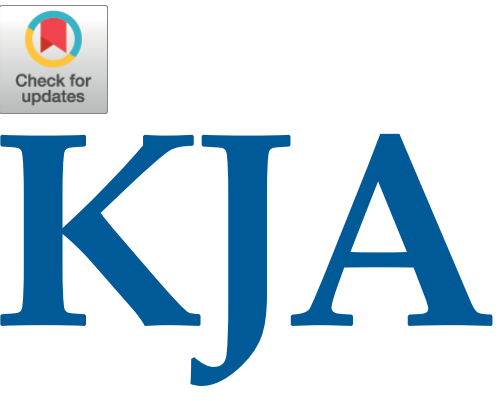

Korean Journal of Anesthesiology

\section{Corrigendum}

Korean J Anesthesiol 2020;73(6):572

https://doi.org/10.4097/kja.d.18.00242.e1

pISSN 2005-6419• elSSN 2005-7563

\title{
What is the proper way to apply the multiple comparison test?
}

\section{Sangseok Lee ${ }^{1}$, Dong Kyu Lee ${ }^{2}$}

${ }^{1}$ Department of Anesthesiology and Pain Medicine, Sanggye Paik Hospital, Inje University College of Medicine, ${ }^{2}$ Department of Anesthesiology and Pain Medicine, Guro Hospital, Korea University School of Medicine, Seoul, Korea

Korean Journal of Anesthesiology 2018;71(5):353-360.

https://doi.org/10.4097/kja.d.18.00242

The article Lee S and Lee DK, "What is the proper way to apply the multiple comparison test?" contained an error in the first appeared equation on page 353.

Before correction:

$\mu \mathrm{A} \neq \mu \mathrm{B} \neq \mu \mathrm{C}$ or $\mu \mathrm{A} \neq \mu \mathrm{B}=\mu \mathrm{C}$ or $\mu \mathrm{A}=\mu \mathrm{B} \neq \mu \mathrm{C}$ or $\mu \mathrm{A} \neq \mu \mathrm{C}=\mu \mathrm{B}$

The correct infomation is found below:

$\mu \mathrm{A} \neq \mu \mathrm{B} \neq \mu \mathrm{C}$ or $\mu \mathrm{A} \neq \mu \mathrm{B}=\mu \mathrm{C}$ or $\mu \mathrm{A}=\mu \mathrm{B} \neq \mu \mathrm{C}$ or $\mu \mathrm{A}=\mu \mathrm{C} \neq \mu \mathrm{B}$

The authors would like to apologize for any inconvenience caused.

\footnotetext{
(C) The Korean Society of Anesthesiologists, 2020

(C) This is an open-access article distributed under the terms of the Creative Commons Attribution Non-Commercial License (http://creativecommons.org/licenses/ by-nc/4.0/), which permits unrestricted non-commercial use, distribution, and reproduction in any medium, provided the original work is properly cited.
} 